\title{
Key criteria of sustainable hospital refurbishment
}

\author{
Ali Hashim Yas ${ }^{1}$, Aymen J. Alsaad ${ }^{2}$, Muntadher J. Taher ${ }^{3}$ \\ ${ }^{1}$ College of Engineering, University of Kerbala,56001, Karbala, Iraq. \\ ${ }^{2}$ Department of Civil Engineering, College of Engineering, University of Kerbala, 56001, Karbala, Iraq . \\ ${ }^{3}$ Imam Hussein Holy Shrine, Karbala, Iraq. \\ ${ }^{4}$ Department of Civil Engineering, College of Engineering, University of Warith-alanbiyaa, Karbala, Iraq.
}

\section{Article Info}

Received, 2019

\section{Keyword:}

Sustainable, Refurbishment, Hospital,

Restoring,

Ventilation,

Structure.

\begin{abstract}
The primary function within a hospital is administering care to patients. Physicians and nurses are the main caregivers within hospitals and since the establishment of the modern hospital institution. They are the main stakeholders in healthcare. Many studies have been done on the aspects of sustainable environment in hospitals and evidence-based design and this study will, according to the research set. We expounded on what constitutes a sustainable hospital refurbishment from stakeholders. Outline environmental strategies that can be employed to support hospital structural environments. We developed selected sets of design guidelines that can be employed in hospital design and planning to support sustainable and refurbished environments. This research is of significance to the domain of hospital planners and designers as it extends the knowledge base that currently exists in environmental strategies for hospital design and with special emphasis to warm and humid climate by the analyses of stakeholders as discussed in this study.
\end{abstract}

\section{Corresponding Author:}

Ali Hashim Yas,

College of Engineering,

University of Kerbala,

56001, Karbala, Iraq.

Email: aliyas40@yahoo.com

\section{Introduction}

Hospitals reflect a manifestation of the health care system and are in essence the spaces and institutions through which healthcare is administered to the public and are central to the process of healthcare. As such, they contribute to a large extent, the health quality of the population through the services they offer. Such Hospitals as National Hospital and Referral Hospital determine access to specialist services, have a major impact on overall health care industry through their policies and initiatives and provide professional leadership. It is with this reason that such hospitals should be effectively organized and designed to provide positive impact on health and well-being for its users.

Healthcare has been encountered with various challenges in terms of patient care and cost stemming from planning and environments within hospitals. While there exists healthcare facilities within the region that have been designed to a certain level of success and efficient service providence, there still exists disconnect between healthcare as relates to patient and staff well-being, patient healing, stress reduction and safety.

There is need to re-evaluate healthcare provision and facilities to a level of affordable and sustainable healthcare that will be havens of hope and easy access to the communities around. Progressively, it is clear that in order to achieve sustainable healthcare that in turn doesn't do harm to the environment and accentuates 
patient care, there is need to re-evaluate how hospitals are designed with special emphasis on patient and staff comfort within the hospital environment.

There has been much written on the subject of environmental hospital design over the last thirty years and this research will limit itself to the most recent and current study and that which presents itself to sustainable environments in the hospital environments [1].

Since quite a substantial amount of literature has been studied on healthy buildings, it is nearly impossible to report on all of it within the time frame provided hence only the most poignant literature has been selected.

\subsection{Objectives of study}

There is need is to establish, within the building industry and specifically within the healthcare industry, a set of criteria and strategies that can govern the way in which hospital environments develop as shown in figure 1 and are designed to create healthy living spaces that, as a result, do not harm either the planet or the occupants.

This research is of significance to the domain of hospital planners and designers as it extends the knowledge base that currently exists in environmental strategies for hospital design and with special emphasis to warm and humid climate.

The findings which have resulted from each case study have the capacity to impact upon the processes by which hospital environments are designed. The thesis will propose strategies by which all those involved in the building process can create, for themselves and for others, healthy living spaces that reduce nosocomial infection rates and that are comfortable living environments. These are the strategies within architecture that can inspire, create and maintain health.

\subsection{Problem statement}

There is a general lack of open spaces for positive distractions in hospitals and the indecent lighting conditions in these hospitals cause patient depression, confusion and staff medical errors. This creates a paradox in which the healthcare industry is contributing to the very problem it is trying to solve. So a review of sustainale services in hospitals would developed and evaluated in this research. This study therefore seeks to understand the causes for the mismatch and propose solutions towards directing hospital design towards patient and staff well-being, patient healing, stress reduction and safety of hospital occupants.

\section{2. Background}

The process of healing in a hospital is departmentalized with every department providing care at a higher and supportive role to the previous. These departments are mainly outpatient, diagnostic and treatment, inpatient, administration and service departments. Higher level hospitals have the research and training departments.

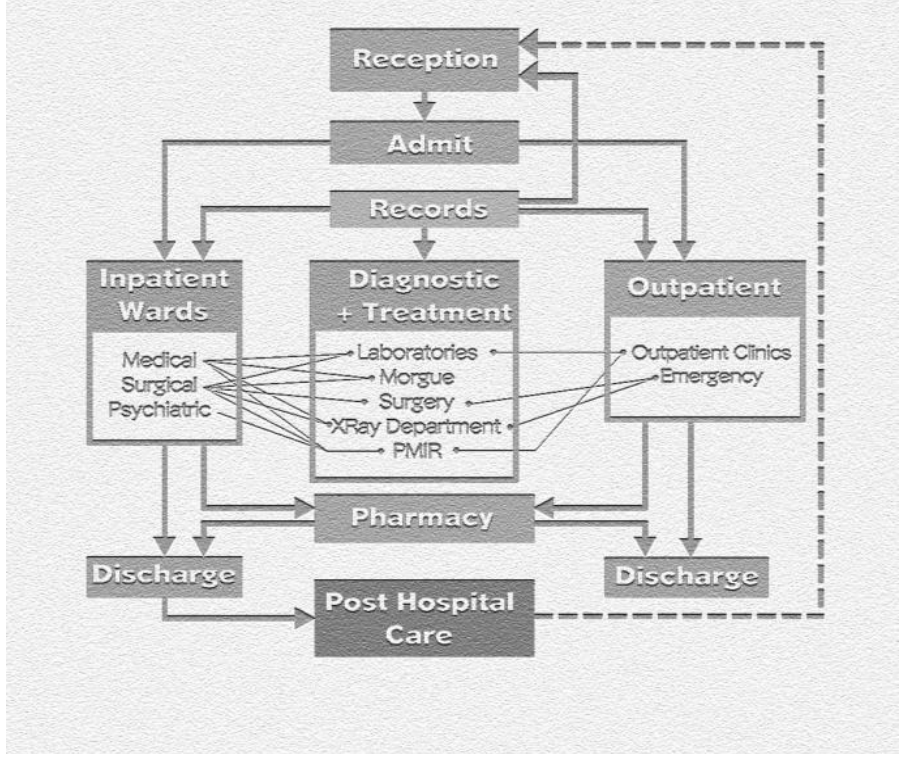

Figure. 1 The process of sustaining mainly revolves around the outpatient, diagnostic and treatment and the inpatient departments for the patient, physician, nurses and visitors. These are the environments within which they operate through the process of healing to the patient. [4] 
The process of healing mainly revolves around the outpatient, diagnostic and treatment and the inpatient departments for the patient, physician, nurses and visitors. These are the environments within which they operate through the process of healing to the patient.

The patient flow system begins from the reception area where nurses in the triage and nursing stations tend to the patient in the waiting areas (Outpatient). Patients then see the doctor in consultation rooms (Diagnostic and Treatment) where they are diagnosed by the physician. The patient proceeds to the laboratory, surgery or Pharmacy depending on the diagnosis. Alternatively, the patient may be led to the Inpatient Department where General, Paediatric and ICU wards are located. Nurses mainly man these stations by providing prescriptive and emotional support until the patient is discharged. This is the typical patient flow in a hospital that forms the process of healing within hospital environments [2].

Medicine, physician and nursing care forms a pivotal part of the healing process and is a major part of the healing process. Such environments where the patient, staff and visitors resides in therefore needs to enhance the feeling and tasks that a hospital environment houses. Doctors and patients need to be in a relaxed and right state of mind when administering healthcare to the patient. The patient on the other hand needs to be receptive and calm for a holistic take to medical care.

\subsection{Ventilation and indoor air quality}

Ventilation in a building is the ultimate need more than any other aspect in design. it is the basic need to sustain life and has been researched in hospital environments by different studies towards providing optimum indoor air and thermal quality. (Burpee, 2009, Li et al, 2007; Tang et al, 2006; Brager, 2004). [3]

Natural Ventilation strategies have been noted to support thermal comfort in hospital buildings by maintaining comfortable temperature levels, reducing nosocomial (Hospital Acquired Infection) rates by cutting spread of air borne diseases like TB and also reduce Operational costs through minimal use of artificial systems (Tang et al, 2006) [4-5].

Li et al in the 2007 study notes that there is compelling evidence on the link between ventilation, air movement in buildings and the spread of infectious diseases such as Severe Acute Respiratory Syndrome (SARS), Measles, Tuberculosis, Influenza, Smallpox and Chickenpox.

Observational cases like the Butaro District Hospital by Mass Design have been proved through continuous studies that natural ventilation strategies can help reduce nosocomial infection rates of air borne diseases through ventilation strategies. (Mass Design-Report 2012) [6].

\subsection{Environmental design strategy}

Evidence Based design which results in controlling natural environments are selective of the specific environments in which the design is to be done. Hawkes et al. 2002, [7] states effective application of these design strategies aims to achieve internal environments that are as far as possible naturally sustained and which its comfort conditions are related to the climate of their location.

In hospital design, a change in natural environmental will result in a shift of how the four environmental strategies (Lighting, Sound Quality, Views and Gardens and Ventilation are applied. As such there needs to be mutually beneficial relationship between nature and architecture. This study seeks to develop certain building guidelines that can be utilized in warm and humid climate at the coast [8-9].

According to Charles Hooper in his Book Design for Climate, Guidelines for the Design of Low Cost Houses for the Climates of, the five key elements that govern design within specific climatic regions are:

- Human Comfort; Day and Night comfort

- Site Planning; Choice of site, housing layouts, Spacing of units and Vegetation/Plants.

- Unit Plan; Unit form, Orientation, Courtyards, Verandas, Units on stilts and Ceiling heights.

- Structure and Materials; Lightweight structures, availability and durability of materials, roofs, walls and surface finishes.

- Openings of the Building Units; Area of openings, Location of opening, Window types, Louvre shutters, Permanent openings, Solar control, Security, Fly-screens and Internal openings. 


\section{Methodology}

An emphasis will be placed on the four major strategies that were identified in the literature review and how they affect patient comfort and staff productivity. This goal will be attained through the development of the objectives stated below and accomplishment of tasks related to each project:

1. To examine current literature and to identify the levels to which environmental strategies are incorporated in hospitals and their importance for the patient's health, well-being, safety, and operation of the facilities. The expected benefits of an environmentally sound hospital will also be evaluated.

2. To study and document hospital projects with varying degrees of environmental soundness and conduct comparative analysis to identify any patterns and differences. The first step is to identify the various strategies present within the hospital environment. This information will be collected by visiting the consultants for the project and illustrate drawings. This will also focus on identifying key features that are most important in hospital environments.

The study will involve a multiple case study approach to compare the varying successes of implementation of healing environments in hospitals. The three cases studied are the Hospital. All of them belong to the same climatic conditions i.e Warm and humid climate, are all 'Level 4' District hospitals according to the Ministry of Health Hospital Class and employ Community Place- making(unbundled) model of site distribution of departments [10].

The research methodology will adopt a three cleft approach. This will involve:

\section{Finding out what exists in the field:}

Establishing the conditions of the hospitals and the strategies that they have employed towards healing environments. Studying these strategies vis-a-vis their performances towards patient comfort, visitor satisfaction and staff comfort and safety.

\section{Finding out what is needed:}

Determining the architectural interventions that can be made to better the existing situation.

\section{Making Recommendations:}

After a careful study and analysis of the area, appropriate recommendations will be made. These proposals will offer design guidelines for professionals in the building industry and stakeholders in healthcare towards better hospitals that support healing and lower operational costs.

\subsection{Data Presentation and Analysis}

The main goal of this research is to identify and verify environmental strategies employed in hospital design towards supporting healing and how they impact the healing process in a hospital. The factors considered crucial have been identified through a critical analysis of the literature review.

An emphasis is placed on how the selected four natural environment elements (lighting, ventilation, sound quality and views) have been incorporated in hospital design through looking at the following key spaecys within building design as applied to the hospital environment.

This seeks to determine the outlook of these elements within the cases vis-a-vis inferences from critical literature on designing hospital with natural environments in mind towards creating healing environments [11].

This research is exploratory in nature, and therefore a case study approach has been identified as the main research strategy. The case study approach provides the best opportunity for contrasting and comparing similarities and differences between each of the three hospitals adopting varying degrees of natural environments towards supporting healing.

Key strong points for the Hospital include:

- Access to public transportation.

- Recycling of water. 
- Use of natural ventilation strategies and views.

- A healing garden inside a courtyard arrangement with shaded gazebo and water fountain. Reduce pavement outside and incorporation of large green areas.

- Highly reflective membrane roof.

\subsection{Flow Diagrams of Sustainable Design}

\subsubsection{Sustainable Design (study-1)}

The flow diagram suggests that the outpatient and the inpatient departments are the core departments for the hospitals and as such these are the environments within which physicians and nurses operate through the process of healing to the patient.

Doctors and nurses will therefore spend a large amount of time in the inpatient and outpatient departments and patients in inpatient will require that the environments that surrounds them be optimum and conducive for enhancing healing.

As such, the focus areas in these three cases will mainly be the outpatient departments and largely the inpatient department i.e. the patient wards.

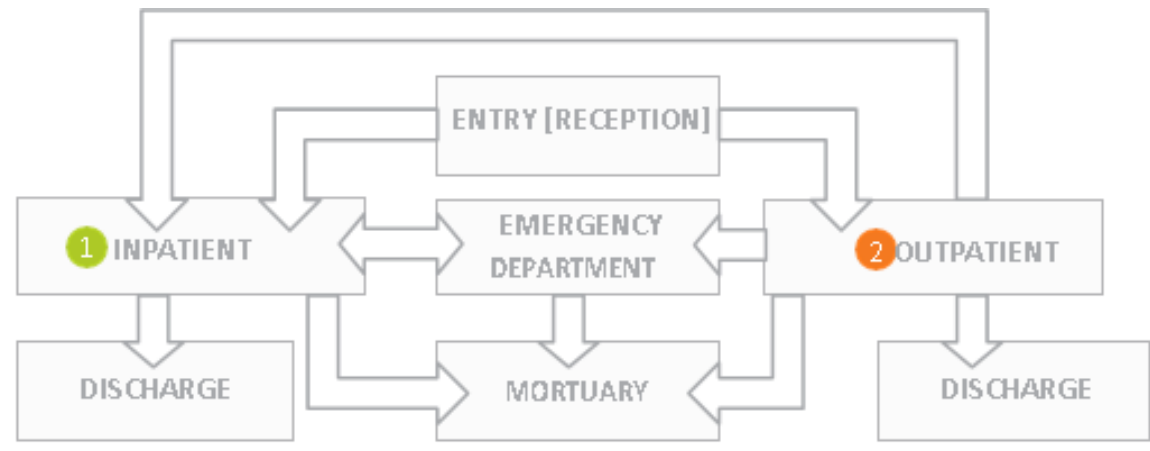

Figure 2. The patient flow process at the Hospital onlt differs from the conventional hospital patient flows at the mortuary level where the hospital has a holding room. As such the inpatient and outpatient department still form the core departments for the hospital patient flow.

\subsubsection{Sustainable Design (study-2)}

The site in the Majengo area is a sheltered site between highly dense residential area where air movement may be hindered due to the density and exposure to prevailing winds. The site is generally tarmacked with no green areas or gardens which results in glare towards the East and west facing facades of the inpatient building which houses the main patient wards.

Average percentage of green areas in the site is less than one percent with only a small patch of grass. The site has no trees incorporated within its design except one small shrub that has since been cut down to create more room for parking spaces.

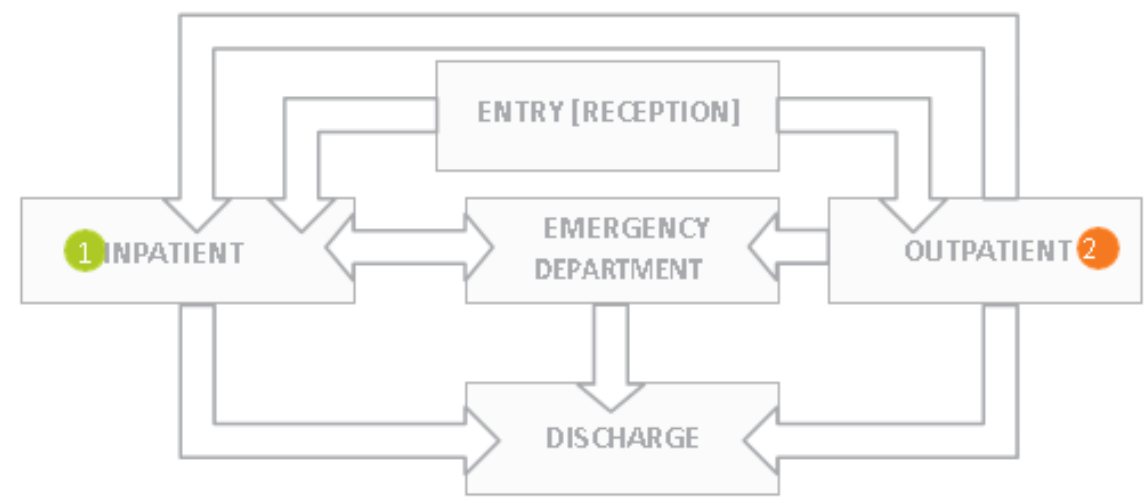

Figure 3. Process of healing at the Hospital are similar from the entry to discharge areas with inpatient and outpatient department being the areas of focus. 


\subsection{Sustainable Hospital Site Planning}

\subsubsection{Natural Lightning}

In site planning, Hospital towards natural lighting in hospital is hindered by the arrangement of the blocks on site and the configuration of the buildings which are deep plan and spacing too close hence limiting light and leading to high reliance of artificial lighting.

Also the little vegetated site leads to glare in building through reflectivity. Hospital have open planning principles with vegetated parts incorporated hence reduced glare into buildings and more ambient diffused natural lighting. Natural lighting is possible to each building department since they are separated form each other to provide more surfaces for lighting.

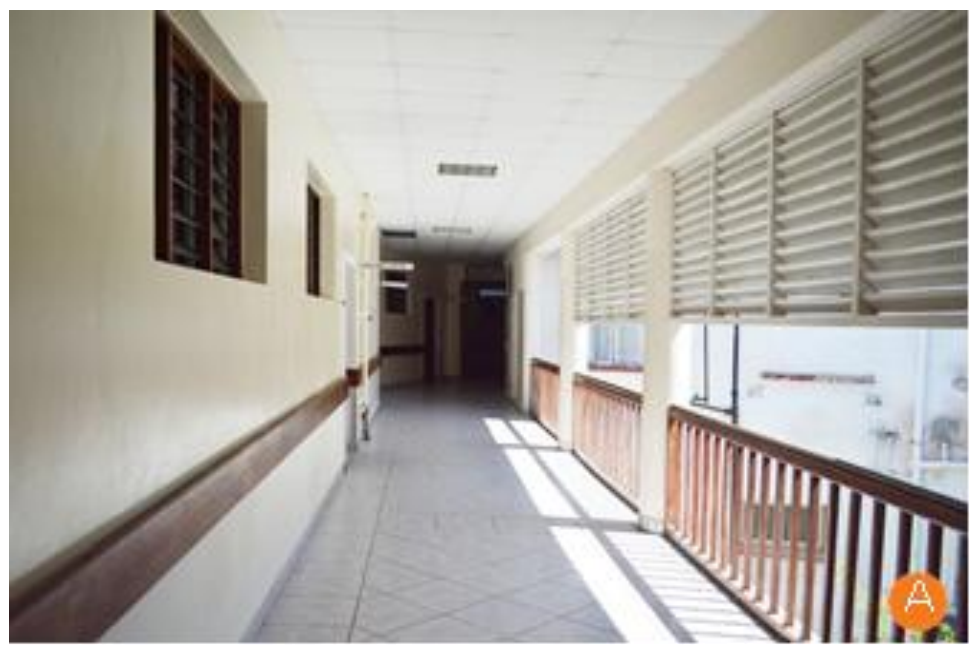

Figure 4. Reviewing sustainable site planning with natural lighning.

\subsubsection{Natural Ventilation}

The Hospital site in the area is a sheltered site between highly dense residential area where air movement may be hindered due to the density and exposure to prevailing winds. The Hospital site is located next to the ocean with direct prevailing breezes to the wards and office spaces. The Hospital site is located on an open site with access to prevailing breezes that are tapped with design towards cross ventilation and thermal comfort.

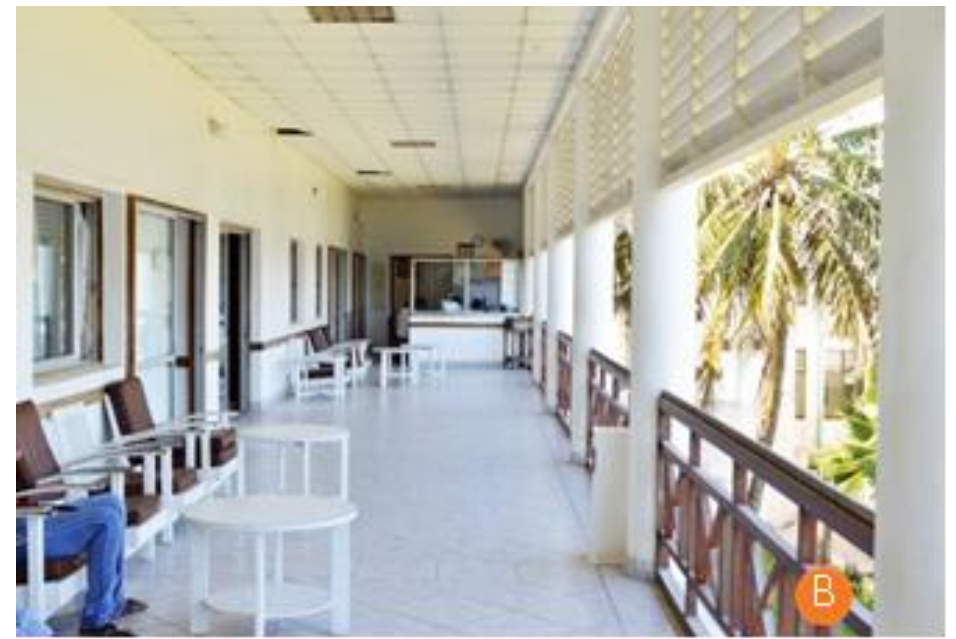

Figure 5. Reviewing sustainable site planning with natural ventilation.

\subsubsection{Sound quality and noise}

The compact nature of the buildings at Hospital, especially the inpatient building which is a deep plan conglomeration of all inpatient, administration and accounting department, contributes to high noise levels in 
terms of human traffic within them. The small site located on a busy lane also hinders spreading of buildings hence compounded high noise levels. Hospitals are located on expansive lands with open plan community place-making approach to design arrangement to minimize noise to departments and also the location of wards and critical ICU rooms in isolated areas and buffered by trees and shrubs reduces noise levels. Hospital units have been located to the inner-most part of the site with surrounding buffers of green areas to avoid traffic noise.

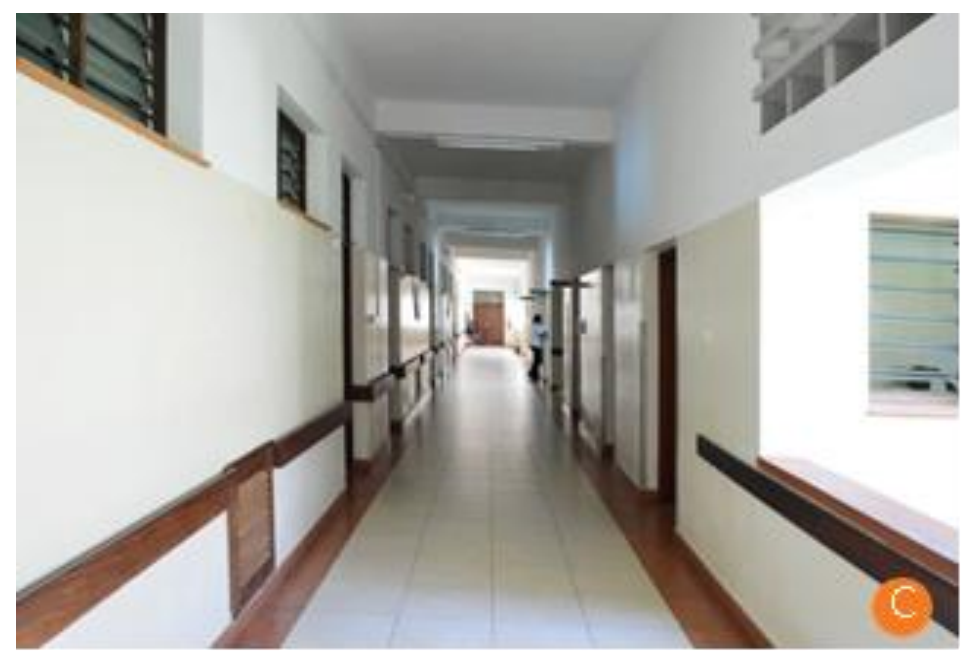

Figure 6. Reviewing sustainable site planning presenting sound quality and noise analysis.

\subsubsection{Views and gardens}

Hospital site is generally tarmacked with no green areas or gardens which results in glare towards the East and west facing facades of the inpatient building which houses the main patient wards. There is also limited views and open spaces for interaction with nature.

The Hospital provides for expansive green spaces with almost 30 percent and 25 percent respectively of the site being vegetated with grass, palm trees and creepers. Such vegetated areas are located next to buildings and patient wards sites hence reducing glare and enhancing natural lighting to indoor spaces while still maintaining good open spaces for users to have views and positive distractions.

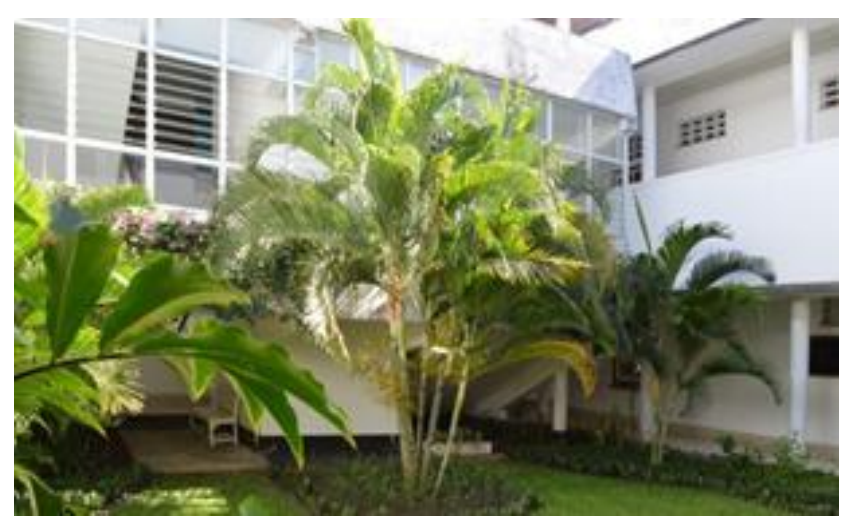

Figure 7. Reviewing sustainable site planning with views of garden for patients.

\section{Results}

From the findings obtained following the study on environmental design of hospital environments towards enhancing healing and conclusions drawn, it is evident that there needs to be interventions in the architecture and design of hospital environments within island (warm and humid climate) and by extension the larger coastal towns experiencing similar climate. 
We draw a few recommendations which can be adopted in design of hospital environments towards enhancing healing in warm humid climates and East African coastal cities by extension. These recommendations will be discussed broadly under the following three tenets.

- Environmental-Design Strategies

- Public Awareness on Hospital design for Designers as well as hospital space use by medical practitioners and patients

- Recommendations for future research on hospital design for other climatic regions.

\subsection{Stakeholder analysis}

The hospital inpatient building should have all elevations with louvred windows that should be openable and a sample wall (A) is about $22.5 \%$ glazed compared to the $20 \%$ required which does well to be sufficient for natural day-lighting. The hospital inpatient building has windows on East West elevations with both louvred windows and sliding fixed light windows that are openable and a sample wall (A) is about $26.5 \%$ glazed compared to the $20 \%$ required which does well to be sufficient for natural day-lighting whilst hospital inpatient building has windows on North South elevations with both louvred windows and sliding fixed light windows that are operable. The percentage of North wall openings is about $42.1 \%$ of the total wall area to the $40 \%$ required.

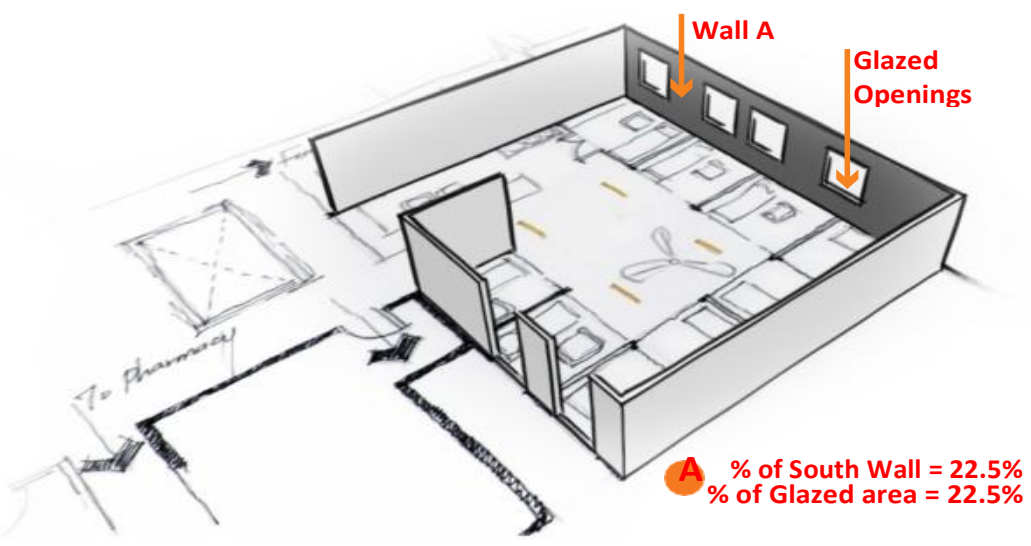

Figure. 8: Workflow for the execution process to be sufficient for natural day-lighting.

The glazed area is $23.1 \%$ to the $20 \%$ required for optimum ambient day- lighting and reducing glare. The unglazed perforated area above the glazed windows acting as permanent ventilation is $19.5 \%$.The South wall has $14 \%$ perforated with no glazing. The author notes that this has led to good cross ventilation and air movement. However, it has hindered light penetration into the inner spaces hence leading to dark interior wards making natural light in the wards deficient.

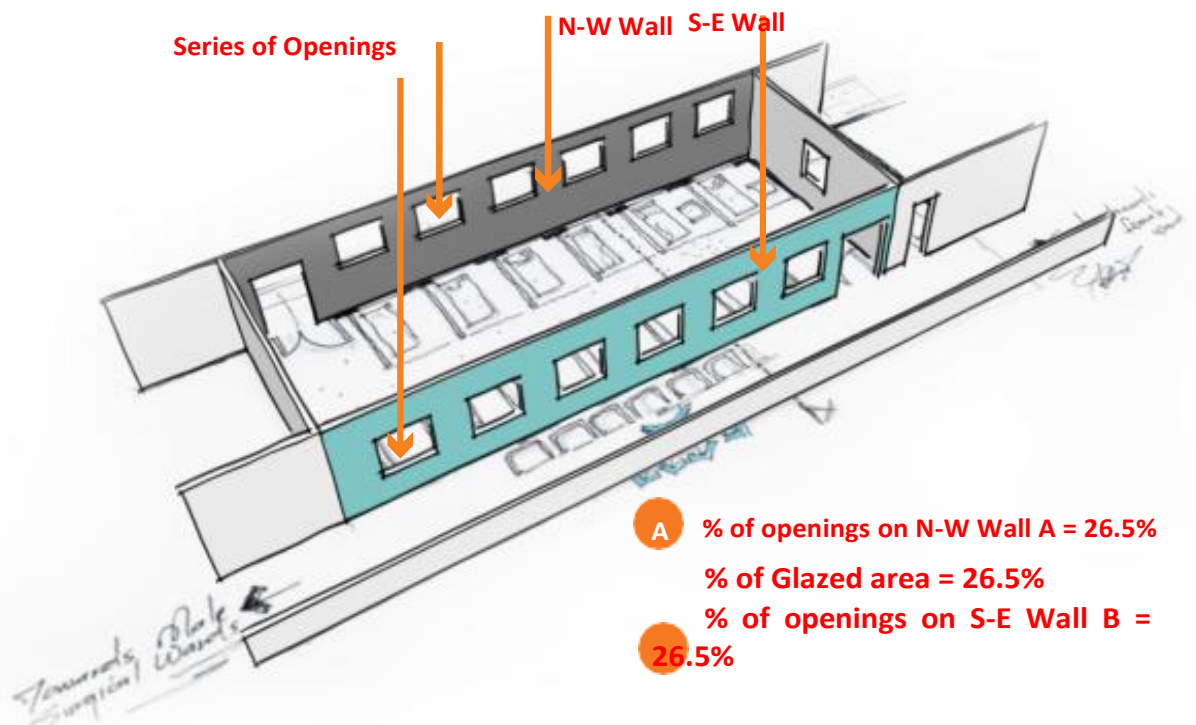

Figure. 9: Workflow for the execution process acting as permanent ventilation. 
All cases have windows located on opposite each other to avoid dead air-pockets thus encouraging cross ventilation. Sill heights vary from $900 \mathrm{~mm}$ in Hospital which has louvred windows directing air downwards to patient beds and seats and as low as $650 \mathrm{~mm}$ high in Hospital which facilitates good comfort levels to patients in low level beds and ventilation to patients seated in low chairs. It further allows for ambient natural lighting that is diffused during the day.

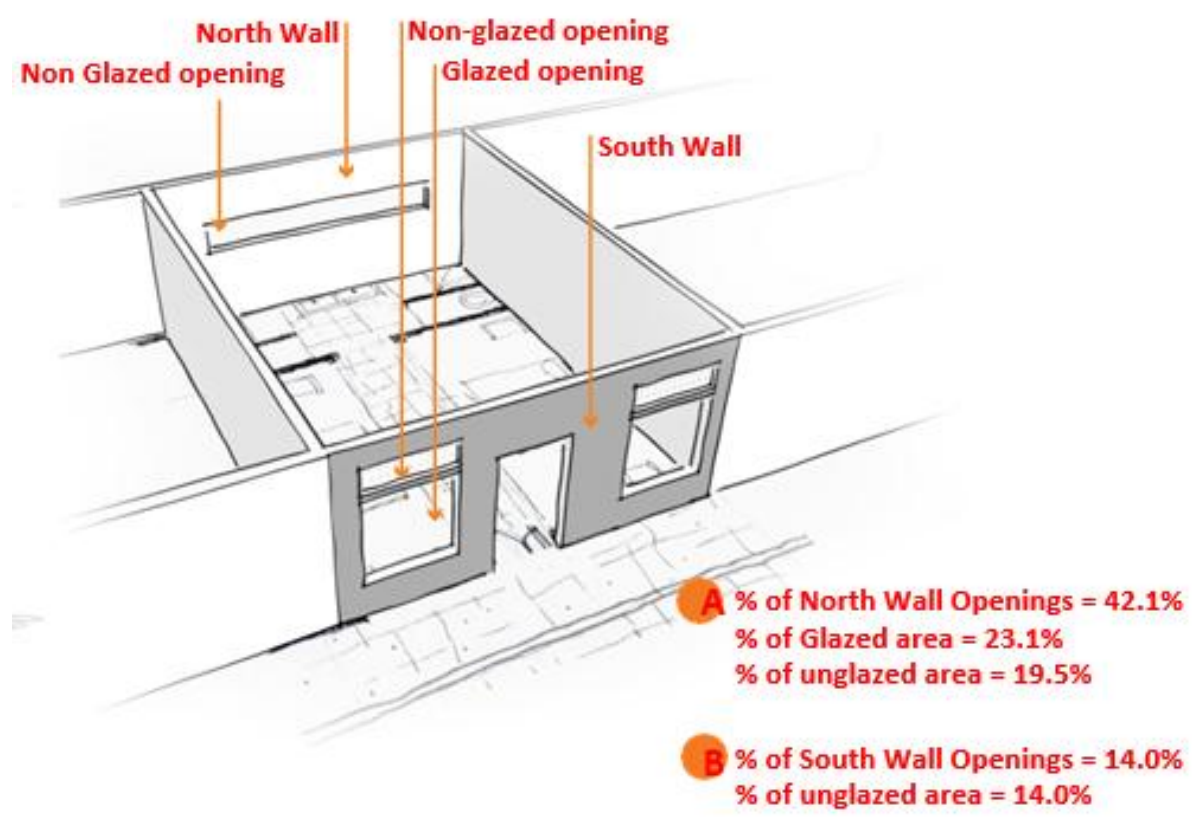

Figure. 10: Workflow for the execution process for encouraging cross ventilation.

\subsection{Evalutaion of hospital structure}

All the cases studied have heavyweight materials which were found appropriate depending on the scale of the building and the detailing of the project in reference to the other variables considered.

Hospital have flat concrete roofs and walls with uses high thermal mass walls. The roofs have high surface areas exposed to the sun hence the large exposed surface area increase heat gain during overheating periods leading to uncomfortable environment within patient wards. Hospital however has asphalt insulated roof which reflects away heat and acoustic ceiling that increases speech intelligibility and reduces noise [12].

Hospital on the other hand has large exposed heavyweight gabled roof of timber and clay tiles with space for air movement between the acoustic ceiling and the roof itself leading to good air movement and cross ventilation. This cools the inner spaces and leads to patient comfort.

Hospital have acoustic ceilings that are essential in insulating the space between the roof and the indoor habitable spaces as compared to the flat concrete roof without a ceiling that leads to heating and reduced air movement.

For good structures within hospital design towards healing the buildings require ceilings that reduce noise and enhance sound quality within patient wards and staff areas. Structures should adopt high thermal mass walls and small surface area to roof or if large then insulated to reduce/slow heat gain during overheating periods and reduce/slow heat loss from the building during the cold seasons. This is a feature that the Hospitals have adopted in their design. Hospital however lacks this hence leading to heat build up and glare within internal spaces. It has large buildings that have large exposed surface areas which should use light reflective and insulated materials. 


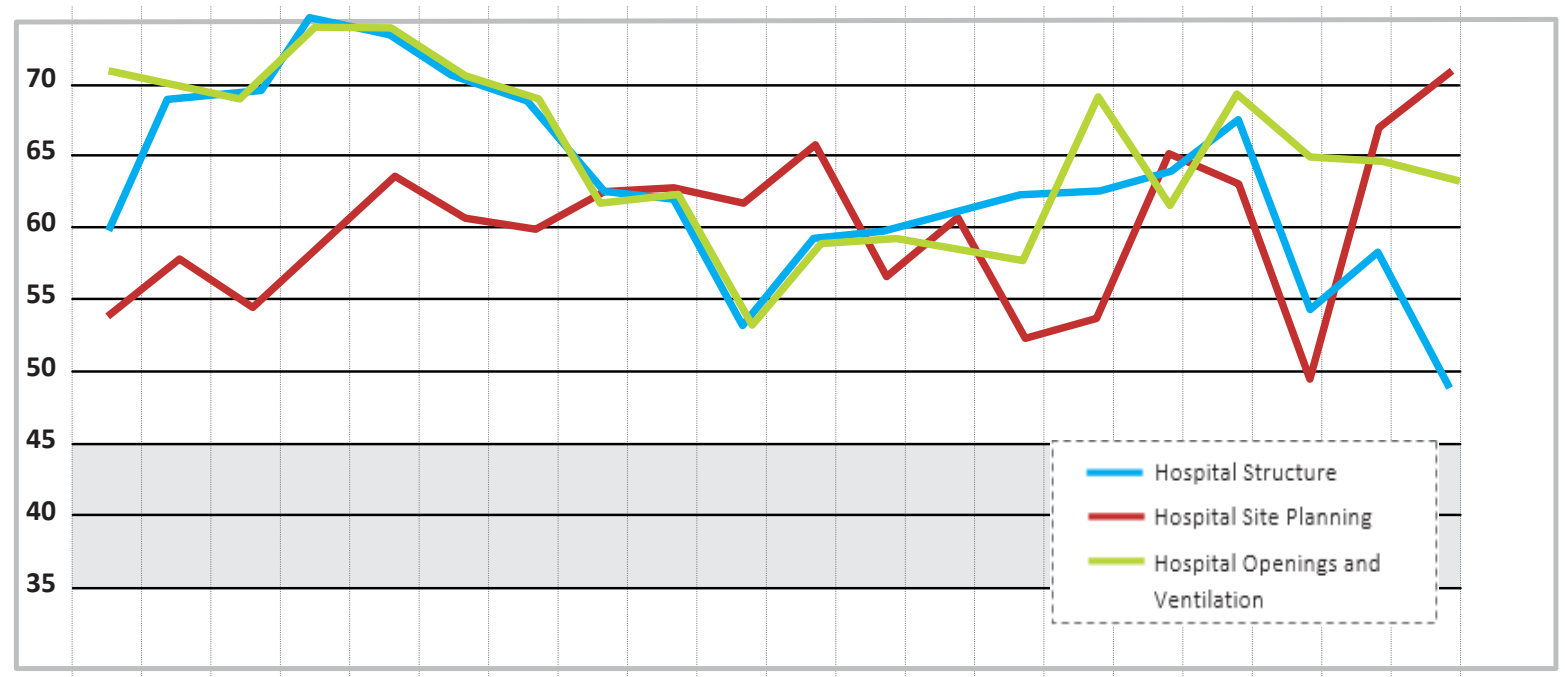

0800- 0830- 0900- 0930- 1000- 1030- 1100- 1130- 1200- 1230- 1300- 1330- 1400- 1430- 1500- 1530- 1600- 1630- 1700- 1730-

0830hrs $0900 \mathrm{hrs} 0930 \mathrm{hrs} 1000 \mathrm{hrs} 1030 \mathrm{hrs} 1100 \mathrm{hrs} 1130 \mathrm{hrs} 1200 \mathrm{hrs} 1230 \mathrm{hrs} 1300 \mathrm{hrs} 1330 \mathrm{hrs} 1400 \mathrm{hrs} 1430 \mathrm{hrs} 1500 \mathrm{hrs} 1530 \mathrm{hrs} 1600 \mathrm{hrs} 1630 \mathrm{hrs} 1700 \mathrm{hrs} 1730 \mathrm{hrs}$

Table 1. Comparative Monitored Data of Sound Pressure Levels in General Male Wards at Hospital (Decibel Levels)

All the three cases have windows and the perforated openings opposite each other to avoid dead air-pockets thus encouraging cross ventilation. This leads to good air movement. Hospital has windows at $900 \mathrm{~mm}$ with adjustable louvred windows hence low level patients in beds and seats get fresh air redirected to them. Hospital has sliding windows that control direct strong sea/land breeze and maintains cross ventilation. Hospital has fixed light windows that hinder air movement when closed at night and early morning. There is however high permanent vents that maintain cross ventilation.

Hospital generally has no pleasant views since the site has no gardens and community spaces. All windows have views to the Majengo area hence the large perceptions by patients are towards these areas. Hospital has expansive glass windows that have views towards gardens and the ocean for positive distraction. Hospital also has large sliding pane windows with introverted views to the courtyard gardens and visual perception of the community spaces. This enhances the well being of the patients and also staff in work environments.

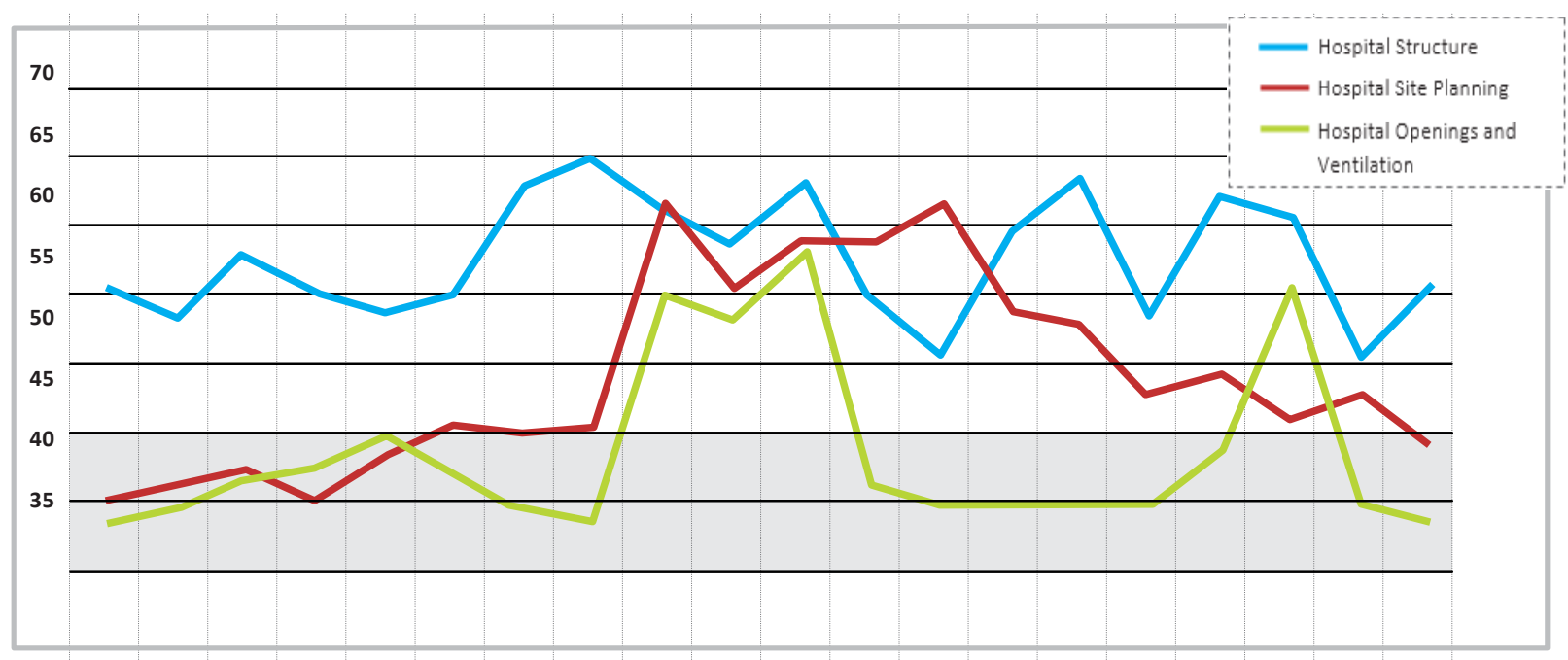

0800- 0830- 0900- 0930- 1000- 1030- 1100- 1130- 1200- 1230- 1300- 1330- 1400- 1430- 1500-1530- 1600- 1630- 1700- 1730 -

0830hrs 0900hrs 0930hrs $1000 \mathrm{hrs}$ 1030hrs $1100 \mathrm{hrs} 1130 \mathrm{hrs} 1200 \mathrm{hrs} 1230 \mathrm{hrs} 130 \mathrm{hhs} 1330 \mathrm{hrs} 1400 \mathrm{hrs} 1430 \mathrm{hrs} 1500 \mathrm{hrs} 1530 \mathrm{hrs} 1600 \mathrm{hrs} 1630 \mathrm{hrs} 1700 \mathrm{hrs} 1730 \mathrm{hrs}$

Table 2. Comparative Monitored Data of Sound Pressure Levels in General Female Wards at Hospital (Decibel Levels) 


\subsection{Stakeholder recommendation}

\subsubsection{Structure}

The hospital should have a heavy weight structure consisting of stone blocks on the walls and a concrete roof with concrete floors.

\subsubsection{Walls}

The outpatient and the inpatient building both should have walls made of masonry blocks which excludes harsh winds but allows direct sunlight in through the perforated blocks within the wall and also windows. The $200 \mathrm{~mm}$ thick wall has low absorption levels for heat and high resistivity. The white paint finishing also allows for reflection of light away hence reducing heat build up towards aiding air movement.

\subsubsection{Roofs}

The roof is a heavy concrete roof with large surface area and should not insulated. It also lacks a ceiling that leads to heat build up and thermal comfort and air movement is compromised. It also has a cone steel and perspex structure for natural lighting which is limited due to its narrow scope of the user areas leading to dark areas within patient wards.

\subsubsection{Surface Finishes}

The walls and the flat roof are exposed to direct sunlight due to the flat roof but should finished in white colour which is reflective to solar heat. This however combined with the inner absence of a ceiling and minimal cross ventilation venues leads to heat build up and poor ventilation.

\subsubsection{Verandas}

The inpatient department at Hospital should have verandahs within their design that overlook the garden spaces that are located in courtyards. Prominence has however been given to courtyards. Additionally, private wards have balconies that add light penetration into the wards as opposed to the general wards. Average light levels in private versus general wards is 250lux in private versus 90lux in general ward. Both however, are still below the 350lux required.

The verandahs should be located towards the North South which is expected to be airier hence experiences a lot of air movement within them that enhances cross ventilation. This exposes the wards to gentle breezes through the wards especially when doors are opened.

\section{Discussion}

Various environmental design strategies within hospital building and space design need to be implemented when designing and constructing a hospital. They are:

i. Careful site selection to ensure that chosen sites are exposed to breezes and in less dense areas to allow for air movement. The sites should not be sheltered form winds and preferably should be away form major noise sources like Factories, schools and highly dense residential areas. Also, sites should have or be designed to incorporate high vegetation growth on site to provide for shade especially in open spaces, views and buffer noise levels form major sound annoyances. Layering approach to site planning of departments i.e. open, informal and well- spaced for natural ventilation in/ around wards and noise buffering should also be adopted.

ii. Patient wards and staff offices should be narrow plan, preferable H-plan and single-banked forms and orientated primarily North-South on longer facades to achieve diffused natural lighting and good winds and cross ventilation. The author also proposes Verandahs and/or balconies essential for shading and eliminating corridors in hospital wards and semi-enclosed garden spaces and outdoor courtyards for patient comfort [13].

iii. Author recommends structures with high thermal mass walls and small surface area to roof or if large then insulated to reduce/slow heat gain during overheating periods and reduce/slow heat loss from the building during the cold seasons. 
iv. Openings should be large, sun-shaded and have low sills i.e from $450 \mathrm{~mm}$. Preferably over half of North and South walls should be open or operable but glazed part should not exceed $20 \%$ of the areas of these walls with the other $20 \%$ of opaque material. Louvred windows, 2 with a combination of glass and aluminium blades, and louvred timber shutters are appropriate for air movements [15].

\section{Conclusion}

reconsidering a sustainable refurbishment of hostiptals is an increasing the general awareness about the benefits of healing environments in hospitals and the ability for good design to enhance healing and patient well being in hospitals would go a long way in changing the behaviour of stake holders in the building industry and healthcare. This impact can be adopted. Specific curriculum changes to schools of architecture on institutional design and public spaces design towards promoting user well being and raising campaigns in promoting environmental designs among hospital developers towards environmental design cost efficiency as an incentive. Patients and staff within hospital environments should be educated on the need to use spaces designed for them well so as to enhance patient and staff well being. Certain features within hospital design like gardens are rarely used by staff and patients due to lack of their benefits hence sensitizing the user of the hospital on good hospital environments. Legislation; it is important to ensure that appropriate regulations are in place and provide relevant guidelines on the hospital industry where there are set bare minimum standards and bench-marking for the hospital industry in terms of construction of hospital environments and maintenance. These regulations should comprehensively cover buildings quality and apply to new upcoming buildings and also towards upgrading existing hospitals that fall short.

\section{Future enhancement}

We recommend that research on hospital design towards enhancing healing is paramount and as such a focus on all climatic regions should be considered towards preparing documents that will be guidelines for environmental spaces within hospitals that will enhance healing. The author notes that other climatic regions especially within like normal climate and hot and dry climate et al should also be studied to come up with templates for comfortable hospital design environments.

\section{References}

[1] E. Pantzartzis, F. T. Edum-Fotwe and A. D. F. Price, "Sustainable healthcare facilities: Reconciling bed capacity and local needs," International Journal of Sustainable Built Environment, vol. 6, (1), pp. 54-68, 2017.

[2] C. Nieto-Sanchez et al, "Home improvement and system-based health promotion for sustainable prevention of Chagas disease: A qualitative study," PLoS Neglected Tropical Diseases, vol. 13, (6), pp. e0007472, 2019.

[3] H. Wu et al, "Environmental Sustainability and Mold Hygiene in Buildings," International Journal of Environmental Research and Public Health, vol. 15, (4), pp. 681, 2018.

[4] B. Durakovic, Yıldız, G., and Yahia, M. E., "Comparatıve performance evaluation of conventional and renewable thermal insulation materials used in buildıng envelops", Tehnicki vjesnik - Technical Gazette, vol. 27, p. In Press, 2020.

[5] T. Winther and K. Gurigard, "Energy performance contracting (EPC): a suitable mechanism for achieving energy savings in housing cooperatives? Results from a Norwegian pilot project," Energy Efficiency, vol. 10, (3), pp. 577-596, 2017.

[6] I. Al Barazanchi, H. R. Abdulshaheed, S. A. Shawkat, and S. R. Binti, "Identification key scheme to enhance network performance in wireless body area network," Period. Eng. Nat. Sci., vol. 7, no. 2, pp. 895-906, 2019.

[7] S. Rashid, A. Ahmed, I. Al Barazanchi, and Z. A. Jaaz, "Clustering algorithms subjected to K-mean and gaussian mixture model on multidimensional data set," Period. Eng. Nat. Sci., vol. 7, no. 2, pp. 448-457, 2019. 
[8] A. A. Sezer, "Factors influencing building refurbishment site managers' waste management efforts," Journal of Facilities Management, vol. 15, (4), pp. 318-334, 2017.

[9] H. R. Abdulshaheed, S. A. Binti, and I. I. Sadiq, "A Review on Smart Solutions Based-On Cloud Computing and Wireless Sensing," Int. J. Pure Appl. Math., vol. 119, no. 18, pp. 461-486, 2018.

[10] I. Al Barazanchi, H. R. Abdulshaheed, S. A. Shawkat, and S. R. Binti, "Identification key scheme to enhance network performance in wireless body area network," Period. Eng. Nat. Sci., vol. 7, no. 2, pp. 895-906, 2019.

[11] I. Al-Barazanchi, S. A. Shawkat, M. H. Hameed, and K. S. L. Al-Badri, "Modified RSA-based algorithm: A double secure approach," Telkomnika (Telecommunication Comput. Electron. Control., vol. 17, no. 6, pp. 2818-2825, 2019.

[12] Anonymous "EBRD, EU and WBIF donors finance energy efficient refurbishment of public hospital in Zenica," Pivotal Sources, 2018.

[13] E. Delzendeh et al, "The impact of occupants' behaviours on building energy analysis: A research review," Renewable and Sustainable Energy Reviews, vol. 80, pp. 1061-1071, 2017. 